\title{
Pilotażowy program badań przesiewowych słuchu u dzieci w wieku szkolnym w Tadżykistanie
}

\section{Pilot hearing screening program in children from primary schools in Tajikistan}

\author{
Piotr Henryk Skarżyński ${ }^{1,2,3}$, Weronika Świerniak ${ }^{1}$, Adam Piłka ${ }^{1,4}$, \\ Karolina Dajos-Krawczyńska ${ }^{1,4}$, Łukasz Bruski ${ }^{3}$, Łukasz Kralczyński ${ }^{1,3}$ \\ ${ }^{1}$ Instytut Fizjologii i Patologii Słuchu, Warszawa/Kajetany \\ ${ }^{2}$ Warszawski Uniwersytet Medyczny, Zakład Diagnostyki i Rehabilitacji Okulistycznej i Narządów Zmysłu, \\ Warszawa \\ ${ }^{3}$ Instytut Narządów Zmysłów, Warszawa \\ ${ }^{4}$ Światowe Centrum Słuchu, Warszawa/Kajetany
}

Adres autora: Piotr H. Skarżyński, Zakład Diagnostyki i Rehabilitacji Okulistycznej i Narządów Zmysłu, ul. Sierakowskiego 13, 03-709 Warszawa, e-mail: p.skarzynski@ifps.org.pl

\begin{abstract}
Streszczenie
W czerwcu 2011 r. podczas kongresu Europejskich Towarzystw Audiologicznych w Warszawie podpisano Europejski Konsensus Naukowy w zakresie wykrywania i leczenia zaburzeń komunikacyjnych u dzieci w wieku wczesnoszkolnym. Idea ta była jednym z priorytetów realizowanych przez Instytut Fizjologii i Patologii Słuchu (IFPS) podczas prezydencji Polski w Radzie Unii Europy w 2011 roku. W wyniku współpracy z zespołem z Tadżykistanu, w listopadzie 2012 roku pilotażowe badania przesiewowe słuchu przeprowadzono wspólnie w dwóch szkołach w stolicy kraju - Duszanbe. Badania wykonano przy użyciu Platformy Badań Zmysłów. Wykorzystano badanie audiometrii tonalnej oraz kwestionariusze dla rodziców i dzieci. Badaniami objęto łącznie 143 uczniów. Wynik pozytywny uzyskano u 34 uczniów (24\%). 24 uczniów wymagało opieki specjalistycznej, łącznie z leczeniem operacyjnym. Badania pozwoliły na walidowanie procedury badań przesiewowych w Azji Środkowej. Odsetek wyników pozytywnych był wyższy niż w Polsce. Pilotażowy program pozwolił zwalidować także centralną bazę oraz system naukowy SZOK w nowej wersji językowej.
\end{abstract}

Słowa kluczowe: badania przesiewowe słuchu • audiometria tonalna • platforma badań zmysłów • niedosłuch wysokoczęstotliwościowy • niedosłuch przewodzeniowy

\begin{abstract}
Signing of European Scientific Consensus took place during EFAS Congress in June 2011 in Warsaw. It covered area of detection and treatment of communication disorders in early school age children. That idea was one of the priorities during Polish Presidency of the Council of the European Union (the second half of 2011). In cooperation with team from Tajikistan pilot study in Dushanbe was performed in November 2012. The study was carried out with the use of the Sensory Examination Platform. Group consisted of 143 children from two randomly choosen schools. Method consisted of pure tone audiometry and 2 questionnaires (dedicated for parents and pupils). There was positive result in 34 cases (24\%). The study allowed to validate screening procedure and data collection within IT system called SZOK in different language conditions. There was higher number of positive results than in polish studies.
\end{abstract}

Key words: hearing screening $\bullet$ school-age children $\bullet$ hearing loss $\bullet$ sensory examination platform $\bullet$ pure tone audiometry

\section{Wstęp}

Narząd słuchu jest niezbędny do prawidłowego rozwoju każdego dziecka. Zarówno rozwój psychoruchowy, jak i emocjonalny mogą być w znaczący sposób upośledzone, gdy dziecko ma problemy ze słuchem. Brak we wczesnych latach życia informacji docierających drogą słuchową w znaczny sposób ogranicza lub wręcz uniemożliwia rozwój mowy. Odpowiednio wcześnie wykryta wada słuchu może być obecnie skutecznie leczona. Jak najwcześniejsza diagnoza pozwala w odpowiedni sposób poprowadzić pacjenta po ścieżce diagnostyczno-terapeutycznej. Niezwykle istotnym elementem są programy badań przesiewowych. Pierwsze doświadczenia w tym 
zakresie, związane $\mathrm{z}$ badaniami przesiewowymi u noworodków, miały w Polsce miejsce ponad 20 lat temu i były prowadzone przez prof. Marię Góralównę. Kolejne badania ośrodkowe odbyły się w połowie lat 90. [1,2]. Od wielu lat rozwijają się na całym świecie różne programy badań przesiewowych słuchu. Do najbardziej popularnych zaliczyć możemy badania przesiewowe noworodków, w ramach których, w wybranych krajach, u prawie wszystkich nowonarodzonych dzieci wykonywane są badania słuchu [3-5]. Zarówno wyniki programu realizowanego w Polsce, jak i badań przesiewowych słuchu u noworodków, które są przeprowadzane w wielu krajach na świecie, jednoznacznie wskazują, że częstość występowania wrodzonych zaburzeń słuchu wynosi od 2 do 7 na 1000 urodzeń [6-8]. Analizując wyniki, przy przeglądzie literatury, należy zwrócić uwagę na metodologię i zasady interpretacji wyników.

W kolejnych latach życia dziecka mogą pojawić się nabyte uszkodzenia słuchu. Możemy też mieć do czynienia z zaburzenia genetycznymi, w których występuje progresywny niedosłuch [9]. Jak podaje literatura, każdy nierozpoznany niedosłuch, nawet niewielkiego stopnia, może znacząco wpływać na rozwój językowy, socjalny i emocjonalny dziecka, a także na jego osiągnięcia edukacyjne [10]. Minimalne ubytki słuchu, szczególnie zlokalizowane tylko w jednym uchu, mogą długo pozostać niezauważone. Ich obecność może powodować trudności z rozumieniem mowy, szczególnie w hałasie, zaburzenia lokalizacji źródła dźwięku, co w sposób istotny może wpływać na występowanie trudności szkolnych. Jak wskazują liczne badania, dzieci z niedosłuchem nie osiągają takich samych postępów w szkole jak ich rówieśnicy dobrze słyszący. Według różnych badań nawet $40 \%$ dzieci w wieku szkolnym $\mathrm{z}$ jednostronnymi ubytkami słuchu powtarza klasę $[11,12]$. Jedną z najczęstszych przyczyn nabytych uszkodzeń słuchu są stany zapalne ucha środkowego. Wysiękowe zapalenie ucha środkowego jest jedną z najpowszechniejszych chorób wieku dziecięcego. Badania w różnych populacjach pokazują, że od $76 \%$ do 95\% wszystkich przebadanych dzieci przynajmniej raz w życiu przebyło tę chorobę w okresie wczesnego dzieciństwa [11]. Rośnie też częstość występowania ubytków wysokoczęstotliwościowych - pohałasowych, związanych ze słuchaniem głośnej muzyki przez słuchawki [13-15]. Wśród innych przyczyn powodujących występowanie uszkodzeń słuchu wylicza się przebyte choroby zakaźne, np. świnka lub odra oraz zapalenie opon mózgowych, urazy mechaniczne oraz perlaki $[2,16,17]$.

Programy badań przesiewowych słuchu prowadzone wśród dzieci w wieku szkolnym pozwalają na szybkie wykrycie występujących zaburzeń słuchu oraz na wczesne wdrożenie odpowiednich działań leczniczych, rehabilitacyjnych i profilaktycznych [18].

W 1999 roku zespół Instytutu Fizjologii i Patologii Słuchu, we współpracy z Brigham Young University ze Stanów Zjednoczonych oraz Uniwersytetem im. M. Curie-Skłodowskiej w Lublinie, przeprowadził pionierskie badania przesiewowe słuchu w różnych regionach kraju w grupie ponad 6200 dzieci i młodzieży w wieku szkolnym. Badania wykazały, że u co 5 dziecka w wieku 6-18 lat występują problemy ze słuchem [18]. Northern i in. (2001) stwierdzają, że 1 na 1000 dzieci rodzi się z ubytkiem słuchu, natomiast 2 kolejnych dzieci nabywa ubytki słuchu w wieku wczesnodziecięcym. Podczas badań przesiewowych słuchu stwierdza się niedosłuch u 10 do $15 \%$ dzieci, z czego większość ma ubytki przewodzeniowe [2,18].

W latach 2008-2011 zespół Instytutu prowadził liczne masowe programy badań przesiewowych, na potrzeby których opracowano unikatowe urządzenia do wykonywania tych badań oraz wdrożono autorskie rozwiązania organizacyjne, pozwalające prowadzić masowe badania przesiewowe. Dzięki tym rozwiązaniom, przy wsparciu różnych organizacji rządowych i pozarządowych, w ciągu 4 lat badaniami objęto ponad 300 tysięcy dzieci w wieku szkolnym. Innowacyjność tych programów polegała na tym, że badania prowadzono nie w dużych miastach, ale objęto nimi małe wiejskie szkoły. Opracowane narzędzia teleinformatyczne pozwalały, przy stosunkowo niskich kosztach, zorganizować i przeprowadzić te badania, poddać je ocenie przez lekarzy specjalistów, którzy wskazali dzieci wymagające dalszej opieki specjalistycznej $[2,18]$. Wyniki badań przesiewowych słuchu u dzieci ze szkół podstawowych wskazują, że obwodowe uszkodzenia słuchu występują od ponad 7\% do blisko $14 \%$ dzieci. Bardzo istotną obserwacją uzyskaną na podstawie wykonanych badań jest fakt, że ponad $60 \%$ rodziców dzieci z uszkodzeniami słuchu nie zauważyło występowania tych problemów oraz że dla ponad 70\% tych dzieci badanie przesiewowe było pierwszym badaniem słuchu. Doświadczenia oraz uzyskane wyniki zaowocowały opracowaniem Europejskiego Konsensusu Naukowego, podpisanego podczas Europejskiej Konferencji Towarzystw Audiologicznych (EFAS) w czerwcu 2011 roku. Pilotażowe programy badań przesiewowych słuchu inicjowane przez zespół Instytutu w różnych krajach są kontynuacją promowania idei wykrywania i leczenia zaburzeń komunikacyjnych u dzieci w wieku wczesnoszkolnym, idei, która była jednym z priorytetów realizowanych przez Instytut podczas prezydencji Polski w Radzie Unii Europy w drugiej połowie 2011 roku [19-21].

W krajach rozwijających się ogólna świadomość dotycząca występowania ubytków słuchu oraz możliwości ich diagnostyki i rehabilitacji jest niska. W krajach tych, z powodu braku urządzeń i wykwalifikowanego personelu, badania przesiewowe nie są prowadzone, a ograniczony dostęp do lekarzy specjalistów może powodować, że odsetek osób z występującymi różnymi zaburzeniami słuchu w populacji jest wysoki [22].

Zespół Światowego Centrum Słuchu Instytutu Fizjologii i Patologii Słuchu zorganizował i zrealizował pilotażowy program badań przesiewowych słuchu w Tadżykistanie, którego celem była prezentacja opracowanych urządzeń oraz rozwiązań organizacyjnych, pozwalających na prowadzenie badań na masową skalę. Badania były przeprowadzone przy wsparciu Narodowego Centrum Medycznego MZ RT (Duszanbe, Tadżykistan), Wydziału Promocji, Handlu i Inwestycji Ambasady RP w Taszkiencie oraz Kliniki Otolaryngologii Tadżyckiego Państwowego Uniwersytetu Medycznego im. Abuali ibni Sino w Duszanbe (kierownik prof. Jamol Cholmatov). Podczas badań pilotażowych wykonano audiometryczne badanie przesiewowe w szkołach, dokonano klasyfikacji wykrytych uszkodzeń słuchu oraz przeprowadzono konsultacje lekarskie. Dodatkowym celem programu pilotażowego było rozpowszechnienie wiedzy na temat potencjalnych przyczyn występowania uszkodzeń słuchu oraz możliwości prewencji, 
Tabela 1. Ogólna liczba uczniów z niedosłuchem oraz częstość występowania niedosłuchów jedno- i obustronnych z podziałem na szkoły

Table 1. The total number of students with hearing loss and the frequency of unilateral and bilateral hearing loss by schools

\begin{tabular}{|c|c|c|c|c|}
\hline \multirow{2}{*}{ Nr szkoły } & \multirow{2}{*}{$\begin{array}{l}\text { Liczba uczniów } \\
\text { objętych badaniami }\end{array}$} & \multicolumn{3}{|c|}{ Liczba i odsetek uczniów } \\
\hline & & $\begin{array}{c}\text { z niedosłuchem } \\
\text { w całym materiale }\end{array}$ & $\begin{array}{l}\text { z niedosłuchem } \\
\text { jednostronnym }\end{array}$ & $\begin{array}{l}\text { z niedosłuchem } \\
\text { obustronnym }\end{array}$ \\
\hline 2 & 110 & $9 \quad(27,3 \%)$ & $4 \quad(44,4 \%)$ & $5 \quad(55,6 \%)$ \\
\hline 15 & 33 & $25 \quad(22,7 \%)$ & $13 \quad(52,0 \%)$ & $12(48,0 \%)$ \\
\hline Razem & 143 & $34 \quad(23,8 \%)$ & $17 \quad(50,0 \%)$ & $17 \quad(50,0 \%)$ \\
\hline
\end{tabular}

diagnostyki, leczenia i rehabilitacji wśród specjalistów i rodziców w Tadżykistanie.

\section{Material i metody}

Pilotażowy program badań przesiewowych słuchu zrealizował zespół Instytutu Fizjologii i Patologii Słuchu przy współpracy z Tadżyckim Uniwersytetem Medycznym. Badania słuchu wykonano w szkołach podstawowych w Duszanbe w listopadzie 2012 r. Badaniami objęto łącznie 143 uczniów w wieku 7-8 lat $\mathrm{z}$ dwóch szkół powszechnych. Z uwagi na występujące znaczne różnice $\mathrm{w}$ zamożności społeczeństwa do badań pilotażowych wybrano losowo dwie szkoły powszechne i ogólnodostępne, rezygnując z badań w szkołach elitarnych - prywatnych, przy czym w jednej z nich językiem nauczania był język tadżycki, natomiast $\mathrm{w}$ drugiej rosyjski.

Audiometryczne badania słuchu wykonano za pomocą Platformy do Badań Zmysłów, innowacyjnego urządzenia teleinformatycznego, łączącego audiometr klasy IV z systemem informatycznym, pozwalającym na komunikację z systemem naukowym „SZOK”, za pomocą którego możliwe jest wykonywanie analiz statystycznych oraz ocena zebranych wyników badań przez lekarzy specjalistów (laryngologów, audiologów, logopedów) [2]. Badania prowadzono $\mathrm{w}$ cichych pomieszczeniach, zgodnie $\mathrm{z}$ procedurą wyznaczania progu słyszenia [23]. Wyznaczono wartości progów słyszenia dla przewodnictwa powietrznego w zakresie częstotliwości od $500 \mathrm{~Hz}$ do $8000 \mathrm{~Hz}$. Za nieprawidłowy wynik badania przyjmowano wartość progu słyszenia wynoszącą $25 \mathrm{~dB}$ i więcej dla co najmniej jednej częstotliwości w przynajmniej jednym uchu [22,24].

Przed badaniem rodzice lub opiekunowie dzieci wyrażali pisemną zgodę na wykonanie badań oraz wypełniali dobrowolną ankietę dotyczącą dziecka na temat potencjalnych przyczyn występowania u dziecka problemów ze słuchem, przebytych chorób, szumów usznych oraz ewentualnych trudności edukacyjnych. Ogółem zebrano 100 ankiet (69,9\% wszystkich ankietowanych) od rodziców dzieci biorących udział w programie pilotażowym. Wyniki wykonanych badań przesłano za pośrednictwem Internetu do systemu naukowego IFPS - „SZOK”, gdzie zgodnie z przyjętym kryterium wyodrębniono nieprawidłowe wyniki badań oraz dokonano podziału na niedosłuchy jednostronne i obustronne.

Następnie specjaliści ze Światowego Centrum Słuchu IFPS na podstawie wyniku badania przesiewowego oraz danych ankietowych, zgodnie z kryteriami opracowanymi podczas programów realizowanych w Polsce, zakwalifikowali dzieci do następujących grup [2]:

- kontrola - te dzieci, które wymagały dalszej opieki specjalistycznej,

- profilaktyka - pozostałe dzieci z nieprawidłowym wynikiem badania przesiewowego, do rodziców których skierowano informacje na temat profilaktyki zaburzeń słuchu oraz czynników mogących powodować pogłębienie wykrytego niedosłuchu lekkiego stopnia.

Ponadto nieprawidłowe wyniki badania słuchu, oddzielnie dla każdego ucha, podzielono na 3 typy audiogramów [11]: - niedosłuchy niskoczęstotliwościowe - LFHL (ang. Low frequency hearing loss) - gdzie wartość progu słyszenia dla częstotliwości $500 \mathrm{i} / \mathrm{lub} 1000 \mathrm{~Hz}$ wynosił przynajmniej $25 \mathrm{~dB}$ HL, natomiast próg słyszenia dla częstotliwości 2000, 4000 i $8000 \mathrm{~Hz}$ nie przekraczał $20 \mathrm{~dB} \mathrm{HL}$;

- niedosłuchy wysokoczęstotliwościowe - HFHL (ang. High frequency hearing loss) - gdzie wartości progu dla częstotliwości $4000 \mathrm{i} / \mathrm{lub} 8000 \mathrm{~Hz}$ były większe od $20 \mathrm{~dB}$ HL, natomiast dla częstotliwości 500, 1000 i $2000 \mathrm{~Hz}$ wartości progu nie przekraczały $20 \mathrm{~dB} \mathrm{HL}$;

- inne - pozostałe nieprawidłowe wyniki badań przesiewowych, gdzie wartości progu słyszenia większe od 20 dB HL występowały dla przynajmniej dwóch dowolnych częstotliwości.

\section{Wyniki}

Automatyczna analiza uzyskanych rezultatów badań przesiewowych słuchu wykonanych za pomocą systemu „SZOK” wykazała, że odsetek dzieci z nieprawidłowym wynikiem audiometrii tonalnej, zgodnie z przyjętym kryterium, wynosi prawie 24\% (34 uczniów). Zaobserwowano, że 50\% tych niedosłuchów (17 uczniów) stanowiły niedosłuchy obustronne (tabela 1).

U dzieci ze szkoły nr 2 w grupie 25 uczniów (tj. 22,7\%) uzyskano pozytywny wynik badania przesiewowego słuchu, natomiast w szkole nr 15 taki wynik uzyskano u 9 uczniów (tj. 27,3\%). W obydwu szkołach zanotowano podobny rozkład niedosłuchów jedno- i obustronnych.

Na podstawie wyników badań przesiewowych oraz zebranych danych ankietowych lekarze audiolodzy i otolaryngolodzy z IFPS zalecili dalszą opiekę specjalistyczną u 24 uczniów (ponad 70\% wszystkich niedosłuchów). Do rodziców pozostałych 10 uczniów z nieprawidłowym wynikiem 
Tabela 2. Liczba oraz częstość występowania poszczególnych typów audiogramów wśród wszystkich uszu z nieprawidłowym wynikiem badania słuchu

Table 2. The number and occurrence of different types of audiograms among ears with abnormal hearing test results

\begin{tabular}{lcc}
\hline \multicolumn{1}{c}{ Rodzaj niedosłuchu } & $\begin{array}{c}\text { Liczba uszu oraz częstość } \\
\text { występowania }\end{array}$ \\
\hline $\begin{array}{l}\text { Niskoczęstotliwościowy } \\
- \text { LFHL }\end{array}$ & 16 & $(31,4 \%)$ \\
\hline $\begin{array}{l}\text { Wysokoczęstotliwościowy } \\
- \text { HFHL }\end{array}$ & 13 & $(25,5 \%)$ \\
\hline Inne-pozostałe niedosłuchy & 22 & $(43,1 \%)$ \\
\hline
\end{tabular}

badania przesiewowego skierowano informację na temat profilaktyki wykrytego zaburzenia słuchu.

Wśród wszystkich uszu z nieprawidłowym wynikiem badania przesiewowego słuchu, 31,4\% (16 uszu) stanowiły niedosłuchy niskoczęstotliwościowe (LFHL), 25,5\% niedosłuchy wysokoczęstotliwościowe (HFHL), natomiast pozostałe $43,1 \%$ stanowiły ubytki słuchu obejmujące wszystkie badane częstotliwości. Ubytki nisko- i wysokoczęstotliwościowe występowały częściej w uchu prawym, natomiast niedosłuchy inne częściej w uchu lewym (tabela 2).

Zaobserwowano, że wśród 17 dzieci z obustronnie nieprawidłowym wynikiem badania słuchu u $5 \mathrm{z}$ nich w obojgu uszach występował niedosłuch niskoczęstotliwościowy.

Wyniki przeprowadzonych badań ankietowych przedstawiono w tabeli 3.

Badania ankietowe pokazały, że w grupie dzieci skierowanych na badania kontrolne tylko u 37\% z nich wykonano wcześniej badanie słuchu oraz że odsetek ten był nieznacznie większy niż w grupie dzieci, u których wynik badania był prawidłowy.

Dzieci z nieprawidłowymi wynikami badania przesiewowego słuchu ponad dwukrotnie częściej były leczone z powodu zapaleń uszu oraz miały katar podczas przeprowadzania badania w szkole. Dzieci te gorzej słyszą nauczyciela stojącego przy tablicy oraz znacznie częściej mają słabe wyniki w nauce.

Występowanie szumów usznych było porównywalne zarówno w grupie dzieci z prawidłowym, jak i nieprawidłowym wynikiem badania przesiewowego słuchu.

\section{Dyskusja}

Wyniki pilotażowego programu badań przesiewowych słuchu wśród pierwszoklasistów z Tadżykistanu wskazują, że 1 na 4 uczniów ma problemy ze słuchem. Liczba ta jest dużo większa w porównaniu z badaniami przeprowadzanymi w Polsce oraz Iranie. W badaniach przeprowadzanych przez Instytut Fizjologii i Patologii Słuchu w 1999 roku wykazano, że 1 na 5 dzieci w wieku szkolnym ma problemy ze słuchem. W Iranie odsetek dzieci z ubytkami słuchu wynosi $9,81 \%$ (1 na 10 dzieci) $[2,11,25]$.

U wysokiej liczby badanych dzieci (34\%) stwierdzono występowanie niedosłuchu niskoczęstotliwościowego. W Nigerii przeprowadzono badania przesiewowe słuchu w 2011 roku. Spośród przebadanych 300 dzieci ponad połowa (167) miała ubytki niskoczęstotliwościowe w uchu prawym, a 39 dzieci w uchu lewym [26]. W badaniach przesiewowych słuchu w USA [24] odsetek dzieci z LFHL wynosił ok. 7,1\%. Różnice w wynikach mogą być spowodowane faktem, że badania w Tadżykistanie były przeprowadzane w okresie jesiennym, kiedy to jest zwiększona zachorowalność na infekcje górnych dróg oddechowych (IGDO) [23]. Badania przeprowadzone przez Dorotę Zarembę z Kliniki Otolaryngologii Audiologii i Foniatrii Dziecięcej UM w Łodzi wykazuja związek między IGDO a czasowym niedosłuchem. Zaobserwowano, że u dzieci często zapadających na IGDO, w wielu przypadkach występują czasowe niedosłuchy przewodzeniowe [27]. Pozwala to przypuszczać, że większość ubytków niskoczęstotliwościowych w badanej populacji ma charakter czasowy. Dlatego też uczniowie, którzy w ankiecie zgłosili występowanie np. nieżytu nosa i u których w badaniu audiometrycznym stwierdzono niedosłuch niskoczęstotliwościowy, zostali skierowani na dodatkowe badania kontrolne.

Tabela 3. Odsetek odpowiedzi na poszczególne pytania badania ankietowego, z uwzględnieniem podziału na uzyskany wynik badania przesiewowego słuchu u dzieci z pozytywnym wynikiem badania przesiewowego

Table 3. The percentage of responses to each survey question with regard to the positive hearing screening test results in children

\begin{tabular}{lccc}
\hline \multicolumn{1}{c}{$\begin{array}{c}\text { Pytanie z ankiety } \\
\text { (odpowiedzi pozytywne) }\end{array}$} & \multicolumn{2}{c}{ Wynik badania przesiewowego słuchu } \\
\cline { 2 - 4 } & Prawidłowy & $\begin{array}{c}\text { Zalecona } \\
\text { profilaktyka }\end{array}$ & $\begin{array}{c}\text { Skierowane na } \\
\text { badanie kontrolne }\end{array}$ \\
\hline Dziecko miało wcześniej wykonywane badanie słuchu & $25 \%$ & $32 \%$ & $37 \%$ \\
\hline Dziecko było leczone z powodu zapaleń uszu & $16 \%$ & $23 \%$ & $34 \%$ \\
\hline Dziecko dobrze słyszy nauczyciela stojącego przy tablicy & $97 \%$ & $86 \%$ & $74 \%$ \\
\hline $\begin{array}{l}\text { Dziecko styszy piski/szumy lub gwizdy gdy usypiasz lub gdy } \\
\text { W pomieszczeniu jest cicho }\end{array}$ & $9 \%$ & $10 \%$ & $53 \%$ \\
\hline Dziecko miało katar w czasie badania & $23 \%$ & $42 \%$ & $29 \%$ \\
\hline Dziecko osiąga słabe i bardzo słabe wyniki w nauce & $12 \%$ & $14 \%$ & $53 \%$ \\
\hline
\end{tabular}


Analiza wyników badań przesiewowych słuchu w Tadżykistanie wykazała, że ubytki nisko- i wysokoczęstotliwościowe częściej występują w uchu prawym niż w uchu lewym. Podobne wyniki zaobserwowano podczas badań prowadzonych w Nigerii [26], gdzie również stwierdzono częstsze występowanie niedosłuchów obejmujących wysokie częstotliwości w uchu prawym. W badaniach tych ubytków wysokoczęstotliwościowych w uchu prawym było niemal 3 razy więcej niż w uchu lewym.

Jak wskazuje Kuppler, najczęściej występującym ubytkiem słuchu jest ubytek jednostronny - dotyczy niemal 3\% dzieci w wieku szkolnym [28]. Częstość występowania ubytków jedno- i obustronnych w badanej grupie jest porównywalna. Spośród 34 uczniów z ubytkami słuchu połowa (17 osób) miała ubytki jednostronne. Z badań przeprowadzonych w Iranie wynika, że niedosłuchy jednostronne stanowią 3/4 wszystkich niedosłuchów [25]. Niskar i wsp. [22] prowadzili badania przesiewowe u dzieci w wieku 6-19 lat. Prawie 15\% dzieci miało nisko- lub wysokoczęstotliwościowe ubytki słuchu, z czego większość stanowiły ubytki jednostronne [28].
Programy przesiewowe pozwalają nie tylko na wykrycie dzieci z ubytkami słuchu, lecz także z innymi zaburzeniami słuchu, np. szumami usznymi. Jak wskazuje literatura, częstość występowania szumów usznych wynosi 13-37,7\% [29]. Analiza danych z kwestionariusza wykazała, że u 9 do $14 \%$ spośród przebadanych dzieci występują szumy uszne. Podczas badań przesiewowych w Polsce wykazano, że niemal 32\% dzieci z prawidłowym słuchem potwierdza występowanie szumów usznych [30].

Uzyskane wyniki potwierdzają, że w krajach rozwijających się świadomość dotycząca zaburzeń słuchu jest niska. Wiele dzieci w wieku szkolnym ma ubytki słuchu, ale często nie są one dostrzegane przez opiekunów i nauczycieli. Tymczasem nawet niewielkie ubytki słuchu mogą powodować trudności komunikacyjne, emocjonalne czy edukacyjne. Dlatego ważne jest wczesne wykrycie zaburzeń słuchu (w tym szumów usznych). Umożliwiają to programy badań przesiewowych, które pozwalają szybko wyselekcjonować dzieci z ubytkami słuchu i z grupy ryzyka, aby jak najszybciej wdrożyć odpowiednie leczenie i rehabilitację, a w ten sposób podnieść jakość życia pacjentów i ich rodzin.

\section{Piśmiennictwo:}

1. Mueller-Malesinska M, Skarzynski H, Oltarzewski M, Szymborski J, Ratynska J. Project of the countrywide data collecting system for neonatal hearing screening programme in Poland. Scand Audiol Suppl, 2001; 52: 197-8.

2. Skarżyński PH, Kochanek K, Skarżyński H, Senderski A, Wysocki J, Szkiełkowska A i wsp. Hearing Screening Program In School-Age Children In Western Poland. Int Adv Otol, 2011; 7(2): 194-200.

3. Paludetti G, Conti G, DI Nardo W, DE Corso E, Rolesi R, Picciotti PM i wsp. Infant hearing loss: from diagnosis to therapy. Official Report of XXI Conference of Italian Society of Pediatric Otorhinolaryngology. Acta Otorhinolaryngol Ital, 2012; 32(6): 347-70.

4. Ciorba A, Hatzopoulos S, Busi M, Guerrini P, Petruccelli J, Martini A. The universal newborn hearing screening program at the University Hospital of Ferrara: focus on costs and software solutions. Int J Pediatr Otorhinolaryngol, 2008; 72(6): 807-16.

5. Yee-Arellano HM, Leal-Garza F, Pauli-Müller K. Universal newborn hearing screening in Mexico: results of the first 2 years. Int J Pediatr Otorhinolaryngol, 2006; 70(11): 1863-70.

6. Arslan S, Işik AU, Imamoğlu M, Topbaş M, Aslan Y, Ural A. Universal newborn hearing screening; automated transient evoked otoacoustic emissions. B-ENT, 2013; 9(2): 122-31.

7. Garabli H, Genc GA, Kayikci MEK, Turkyilmaz MD, Ozturk B, Karabulut E i wsp. Hearing screening protocols of babies with hearing loss risk factors in Turkey. Int Adv Otol, 2010; 6(2): 216-22.

8. Wolff R, Hommerich J, Riemsma R, Antes G, Lange S, Kleijnen J. Hearing screening in newborns: systematic review of accuracy, effectiveness, and effects of interventions after screening. Arch Dis Child, 2010; 95(2): 130-35.

9. Javidnia H, Vaccani JP. Progressive sensorineural hearing loss in children with congenital diaphragmatic hernias. J Otolaryngol Head Neck Surg, 2009; 38(1): 29-31.
10. Westerberg BD, Skowronski DM, Stewart IF, Stewart L, Bernauer M, Mudarikwa L. Prevalence of hearing loss in primary school children in Zimbabwe. Int J Pediatr Otorhinolaryngol, 2005; 69(4): 517-25.

11. Ross DS, Holstrum WJ, Gaffney M, Green D, Oyler RF, Gravel JS. Hearing screening and diagnostic evaluation of children with unilateral and mild bilateral hearing loss. Trends Amplif, 2008; 12(1): 27-34.

12. Holstrum WJ, Gaffney M, Gravel JS, Oyler RF, Ross DS. Early intervention for children with unilateral and mild bilateral degrees of hearing loss. Trends Amplif, 2008; 12(1): 35-41.

13. Taljaard DS, Leishman NF, Eikelboom RH. Personal listening devices and the prevention of noise induced hearing loss in children: the Cheers for Ears Pilot Program. Noise Health, 2013; 15(65): 261-8.

14. Mahboubi H, Oliaei S, Badran KW, Ziai K, Chang J, Zardouz $\mathrm{S}$ i wsp. Systematic assessment of noise amplitude generated by toys intended for young children. Otolaryngol Head Neck Surg, 2013; 148(6): 1043-7.

15. Morata TC. Young people: their noise and music exposures and the risk of hearing loss. Int J Audiol, 2007; 46(3): 111-2.

16. Tarshish Y, Leschinski A, Kenna M. Pediatric sudden sensorineural hearing loss: diagnosed causes and response to intervention. Int J Pediatr Otorhinolaryngol, 2013; 77(4): 553-9.

17. Nelson M, Roger G, Koltai PJ, Garabedian EN, Triglia JM, Roman $S$ i wsp. Congenital cholesteatoma: classification, management, and outcome. Arch Otolaryngol Head Neck Surg, 2002; 128(7): 810-4.

18. Skarzynski H, Kochanek K, Senderski A, Skarzynski PH, Ludwikowski M, Kopaczewski M i wsp. Organization of the Hearing Screening Examinations in Polish Schools in Rural Areas and Small Towns. Cochlear Implants Int, 2010, Suppl.1; 11: 143-7.

19. Skarżyński H, Piotrowska A. Screening for pre-school and school-age hearing problems: European Consensus Statement. Int J Pediatr Otorhinolaryngol, 2012; 76(1): 120-1 
20. Skarżyński H, Piotrowska A. Prevention of communication disorders - screening pre-school and school-age children for problems with hearing, vision and speech: European Consensus Statement. Med Sci Monit, 2012; 18(4): SR17-21.

21. Skarzynski H, Piotrowska A, Szaflik J, Luxon L, Zehnhoff-Dinnesen A, Kaufmann-Meyer M i wsp. European consensus statement on hearing, vision, and speech screening in pre-school and school-age children. Journal of Hearing Science, 2011; 1(2): 89-90.

22. Niskar AS, Kieszak SM, Holmes A, Esteban E, Rubin C, Brody DJ. Prevalence of hearing loss among children 6 to 19 years of age: the Third National Health and Nutrition Examination Survey. JAMA, 1998; 279(14): 1071-5.

23. Śliwa L, Hatzopoulos S, Kochanek K, Piłka A, Senderski A, Skarżyński PH. A comparison of audiometric and objective methods in hearing screening of school children. A preliminary study. Int J Pediatr Otorhinolaryngol, 2011; 75(4): 483-88.

24. Bess FH. The minimally hearing-impaired child. Ear Hear, 1985; 6(1): 43-7.
25. Sarafraz M, Ahmadi K. A practical screening model for hearing loss in Iranian school-aged children. World J Pediatr, 2009; 5(1): 46-50.

26. Oyewumi AM, Adejumo OR. An Investigation of Hearing Loss among School Age Children through Audiological Assesment in Ibadan, Oyo State, Nigeria. Elementary Education Online, 2011; 10(1): 1-11.

27. Czech D, Malicka M, Kott E, Zakrzewska A. Ocena występowania zaburzeń artykulacyjnych u dzieci z nawracającymi infekcjami górnych dróg oddechowych. Otorynolaryngologia, 2011; 10(3): 116-20.

28. Kuppler K, Lewis M, Evans AK. A review of unilateral hearing loss and academic performance: is it time to reassess traditional dogmata? Int J Pediatr Otorhinolaryngol., 2013; 77(5): 617-22.

29. Raj-Koziak D, Skarżyński H, Kochanek K, Fabijańska A. Ocena częstości występowania szumów usznych u dzieci w Polsce. Otolaryngol Pol, 2013; 67(3): 149-53.

30. Raj-Koziak D, Skarżyński PH, Kochanek K, Piłka A, Bartnik G, Skarżyński H i wsp. The prevalence of tinnitus in 7 years old children in Poland. $10^{\text {th }}$ ESPCI Athens, Medimond, 2011; 269-72. 